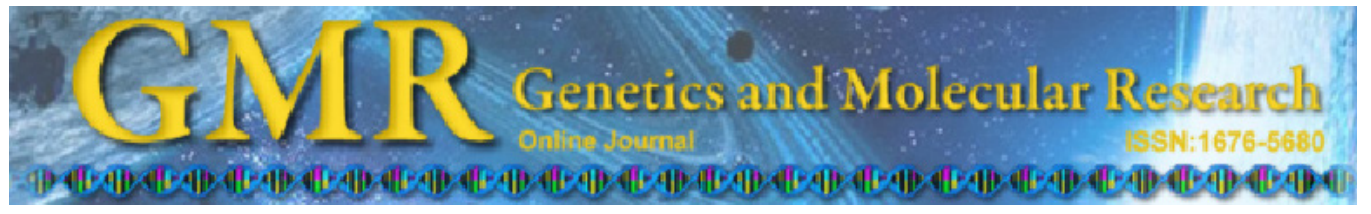

\title{
Relationship between genetic parameters in maize (Zea mays) with seedling growth parameters under 40-100\% soil moisture conditions
}

\author{
R.W. Muhammad ${ }^{1}$ and A. Qayyum ${ }^{2}$ \\ ${ }^{1}$ Arid Zone Research Institute, Pakistan Agricultural Research Council, \\ Bahawalpur, Pakistan \\ ${ }^{2}$ Bahauddin Zakariya University, Multan, Pakistan \\ Corresponding author: A. Qayyum \\ E-mail: raoqayyim@bzu.edu.pk
}

Genet. Mol. Res. 12 (4): 4780-4796 (2013)

Received January 21, 2013

Accepted August 10, 2013

Published October 18, 2013

DOI http://dx.doi.org/10.4238/2013.October.18.15

\begin{abstract}
We estimated the association of genetic parameters with production characters in 64 maize (Zea mays) genotypes in a green house in soil with $40-100 \%$ moisture levels (percent of soil moisture capacity). To identify the major parameters that account for variation among the genotypes, we used single linkage cluster analysis and principle component analysis. Ten plant characters were measured. The first two, four, three, and again three components, with eigen values $>1$ contributed $75.05,80.11,68.67$, and $75.87 \%$ of the variability among the genotypes under the different moisture levels, i.e., 40, 60, 80, and $100 \%$, respectively. Other principal components (3-10, 5-10, and 4-10) had eigen values less than 1 . The highest estimates of heritability were found for root fresh weight, root volume (0.99), and shoot fresh weight (0.995) in 40\% soil moisture. Values of genetic advance ranged from 23.4024 for SR at $40 \%$ soil moisture to 0.2538 for shoot dry weight in $60 \%$ soil moisture. The high magnitude of broad sense heritability provides evidence that these plant characters are under the control of additive
\end{abstract}


genetic effects. This indicates that selection should lead to fast genetic improvement of the material. The superior agronomic types that we identified may be exploited for genetic potential to improve yield potential of the maize crop.

Key words: Genotypic correlations; Principle component analysis; Heritability; Zea mays L.

\section{INTRODUCTION}

Corn ranks third among the cereal crops worldwide after wheat and rice. In Pakistan, maize is cultivated on an area of 950 thousand hectares with total production of 3.487 million tons (Anonymous, 2009-2011) with an average yield of $2892 \mathrm{~kg} / \mathrm{ha}$. It is used as food by humans and feed for the livestock and poultry. It provides the raw material in food, pharmaceutical and textile industries, which finally make corn oil, corn flakes, dextrose, textile dyes, etc. A plant may experience biotic and abiotic stresses in the field, such as diseases, water stresses, water logging, salinity, high and low temperature extremes, etc., either continuously or with some intervals at different times during the growing season (Trester and Bacic, 2005). Abiotic stresses reduce crop productivity (Boyer, 1970; Araus et al., 2002). Among various abiotic stresses drought is undoubtedly one of the worst natural enemies of life. It can occur in any region of the world, and can affect life from very basic personal inconveniences to a nationwide level. Drought can reduce crop yield, pasture deterioration and death of livestock. It strongly affects the production of cereals, and poses a threat to the food security of households. World food security is dependent on continuous crop improvement; in particular, the development of crops with increased tolerance to abiotic stresses, especially drought and salinity (Denby and Gehring, 2005). Maize was grown at three levels of water availability (100, 75 or $60 \%$ of daily transpiration) during a period bracketing silking and at two plant densities (6 and 10 plants $/ \mathrm{m}^{2}$ ) without nutrient limitations to generate a range of levels of resource availability of water (Echarte and Tollenaar, 2006). An earlier study of water stress at 3 growth stages: before silking, at silking and during grain filling caused a significant reduction in the different growth parameters studied at 90 days after planting as compared with the normal irrigation regime (Ghooshchi et al., 2008). The main objective of the present study was to identify the drought tolerant maize genotypes. The study of such traits can help a plant breeder to select the maize genotypes with better yield under drought stress conditions.

\section{MATERIAL AND METHODS}

The proposed study was carried out in a greenhouse at the Arid Zone Research Institute, Bahawalpur, Pakistan Agricultural Research Council, Pakistan, situated at latitude $29.22^{\circ} \mathrm{N}$, longitude $71.38^{\circ} \mathrm{E}$, with an altitude of $112 \mathrm{~m}$. The field temperature ranged between $5^{\circ}$ to $38.7^{\circ} \mathrm{C}$, relative humidity ranged between 74.5 and $79.4 \%$, and rainfall ranged 6 to $12 \mathrm{~mm}$, during 2010. The experimental material consisted of the 64 accessions listed in Table 1.

These accessions were sown in polythene bags $(18 \times 9 \mathrm{~cm})$ filled with sandy loam soil (pH 7.8 and electrical conductivity of $1.7 \mathrm{dS} / \mathrm{m}$ ) in the greenhouse. Screening was done on 
the basis of their survival rate under four moisture levels/treatments, i.e., $\mathrm{T}_{1} 40 \%, \mathrm{~T}_{2} 60 \%, \mathrm{~T}_{3}$ $80 \%$, and $\mathrm{T}_{4} 100 \%$ of field capacity. The moisture levels at field capacity were measured by volume using a moisture meter. Polythene bags were filled with soil or sand or soil and sand $(3: 1,2: 1)$ and were used as experimental units arranged in a two-factor factorial completely randomized design. One seedling was established in one polythene bag. Ten seedlings of each accession were grown in each treatment. Moisture stress treatments were started on the $21 \mathrm{st}$ day after sowing and the required moisture levels of $\mathrm{T}_{1} 40 \%, \mathrm{~T}_{2} 60 \%, \mathrm{~T}_{3} 80 \%$ and $\mathrm{T}_{4} 100 \%$ of field capacity were maintained. After 50\% mortality, half-strength Hoagland Solution was applied to all the experimental units to recover the surviving seedlings. When the plants were four weeks old, two plants from each pot were harvested and carefully separated into roots and shoots. The roots were washed with a $1 \%$ sodium hydroxide solution, to free them from sand particles (Camacho and Caraballo, 1994).

\begin{tabular}{|c|c|c|c|c|c|c|c|}
\hline $\begin{array}{l}\text { Variation } \\
\text { source No. }\end{array}$ & Acc. No. & Parentage & Origin & $\begin{array}{c}\text { Variety } \\
\text { serial No. }\end{array}$ & Acc. No. & Parentage & Origin \\
\hline $\mathrm{V} 1$ & 014867 & LUTAN NO.31 & Pakistan & V33 & 015225 & $003835(02)$ & Pakistan \\
\hline $\mathrm{V} 2$ & 014910 & 000404(04) & Pakistan & V34 & 015210 & $002818(01)$ & Pakistan \\
\hline V3 & 014934 & $000467(04)$ & Pakistan & V35 & 015216 & $003817(01)$ & Pakistan \\
\hline V4 & 014935 & $000470(03)$ & Pakistan & V36 & 015217 & 003823(01) & Pakistan \\
\hline V5 & 014936 & $000472(05)$ & Pakistan & V37 & 015219 & $003824(02)$ & Pakistan \\
\hline V6 & 014955 & $000608(04)$ & Pakistan & V38 & 015220 & $003825(01)$ & Pakistan \\
\hline V7 & 015030 & LINFINHAUNG & China & V39 & 015224 & $003834(02)$ & Pakistan \\
\hline V8 & 015038 & WU302 & China & V40 & 015226 & $003837(01)$ & Pakistan \\
\hline V9 & 015042 & BAI NUE & China & V41 & 015229 & 003843(02) & Pakistan \\
\hline V10 & 015052 & $000955(03)$ & Pakistan & V42 & 015230 & $003845(05)$ & Pakistan \\
\hline V11 & 015055 & $00095(02)$ & Pakistan & V43 & 015233 & $003849(02)$ & Pakistan \\
\hline V12 & 015060 & $000963(02)$ & Pakistan & V44 & 015237 & $003853(02)$ & Pakistan \\
\hline V13 & 015250 & $003870(05)$ & Pakistan & V45 & 015240 & $003856(02)$ & Pakistan \\
\hline V14 & 015063 & 000966(04) & Pakistan & V46 & 015261 & SH 1956 & Japan \\
\hline V15 & 015066 & 000971(02) & Pakistan & V47 & 015262 & P-3282 & Japan \\
\hline V16 & 015081 & 000991(01) & Pakistan & V48 & 015263 & PX-77A & Japan \\
\hline V17 & 015084 & 000995(02) & Pakistan & V49 & 015275 & NS 89A & Japan \\
\hline V18 & 015114 & $001025(01)$ & Pakistan & V50 & 015272 & P 3358 & Japan \\
\hline V19 & 015123 & TEP 65-B241 & Mexico & V51 & 015273 & P 3470 & Japan \\
\hline $\mathrm{V} 20$ & 015125 & TL 78A-37 & Mexico & V52 & 015275 & NS $89 \mathrm{~A}$ & Japan \\
\hline V21 & 015127 & TL 71A-373-384 & Mexico & V53 & 014861 & TAN YU-6 SINGLE & Pakistan \\
\hline $\mathrm{V} 22$ & 015128 & TL 71A-379-386 & Mexico & V54 & 014879 & $000228(04)$ & Pakistan \\
\hline $\mathrm{V} 23$ & 015129 & TL 76B 210 & Mexico & V55 & 015073 & & Unknown \\
\hline $\mathrm{V} 24$ & 015131 & $001152(01)$ & Pakistan & V56 & 015167 & $002275(03)$ & Pakistan \\
\hline $\mathrm{V} 25$ & 015132 & $001157(02)$ & Pakistan & V57 & 015175 & 002333(01) & Pakistan \\
\hline V26 & 015134 & $001205(01)$ & Pakistan & V58 & 015255 & 004023(06) & Pakistan \\
\hline V27 & 015135 & $001280(05)$ & Pakistan & V59 & 015257 & SH-3764 & Japan \\
\hline V28 & 015137 & $001321(01)$ & Pakistan & V60 & 015183 & 002393(01) & Pakistan \\
\hline V29 & 015138 & $001323(05)$ & Pakistan & V61 & Sahiwal-2002 & & Pakistan \\
\hline V30 & 015143 & $001451(02)$ & Pakistan & V62 & Agaiti-2002 & & Pakistan \\
\hline V31 & 015173 & 002308(01) & Pakistan & V63 & EV-5098 & & Pakistan \\
\hline V32 & 015182 & $002398(03)$ & Pakistan & V64 & EV-6098 & & Pakistan \\
\hline
\end{tabular}

The harvested material was then washed with distilled water, wrapped in wet paper towels, and brought to the laboratory where the data were recorded for traits listed in Table 2; analysis of variance for all the characters was carried out according to Steel et al. (1997). The Duncan new multiple range (DMR) test at the 1\% significance level was used to compare the means of the treatments. Genotypic and phenotypic correlations were calculated to determine the association between different traits (Kwon and Torrie, 1964). The average data were 
analyzed by numerical taxonomic techniques using the procedure of clustering and principal component analysis (Sneath and Sokal, 1973). The data were standardized and transformed for single linkage cluster analysis (SLCA) and principle component analysis (PCs) using the MINTAB 13.2 program. Using character variations, the SLCA summarized the position of genotypes in the dendrogram.

\begin{tabular}{lll}
\multicolumn{2}{l}{ Table 2. List of characters with the abbreviations used. } \\
\hline Serial No. & Abbreviations used & \\
\hline 1 & LA & Name of characters \\
2 & RV & Leaf area $\left(\mathrm{cm}^{2}\right)$ \\
3 & LRL & Root volume $(\mathrm{mL})$ \\
4 & PH & Longest root length $(\mathrm{cm})$ \\
5 & RFW & Plant height $(\mathrm{cm})$ \\
6 & RDW & Root fresh weight $(\mathrm{g})$ \\
7 & SFW & Root dry weight $(\mathrm{g})$ \\
8 & SDW & Shoot fresh weight $(\mathrm{g})$ \\
9 & TDMP & Shoot dry weight $(\mathrm{g})$ \\
10 & SR & Total dry matter production $(\mathrm{g})$ \\
\hline
\end{tabular}

\section{RESULTS AND DISCUSSION}

Analysis of variance along with heritability and genetic advance for 64 genotypes indicated significant differences for all the characters under study (Tables 3 to 6).

The highest estimates of heritability ranged between 0.983 (LRL) to 0.997 (RFW) for all characters listed in Table 3. Values of genetic advance ranged between 17.90 for LA and 0.32 for SDW. The coefficient of variability (CV) was in the range of 5.44 to 13.45 .

\begin{tabular}{|c|c|c|c|c|c|c|c|}
\hline Parameters & $\mathrm{MS}(\mathrm{R})$ & $\mathrm{MS}(\mathrm{V})$ & MS(E) & Means $\pm \mathrm{SE}$ & $\mathrm{h}^{2}$ & GA & CV (\%) \\
\hline LA & 0.009 & $494.182 * *$ & 1.740 & $15.972 \pm 0.007897$ & 0.996 & 17.9052 & 8.26 \\
\hline $\mathrm{RV}$ & 0.00732 & $2.35703^{* *}$ & 0.00756 & $1.305 \pm 0.1143482$ & 0.997 & 1.2370 & 6.66 \\
\hline LRL & 0.468 & $129.491 * *$ & 2.169 & $27.094 \pm 0.015480$ & 0.983 & 9.0438 & 5.44 \\
\hline $\mathrm{PH}$ & 0.770 & $178.65^{* *}$ & 2.369 & $26.672 \pm 0.0131599$ & 0.987 & 10.6669 & 5.77 \\
\hline RFW & 0.00300 & $0.97088^{* *}$ & 0.00264 & $0.736 \pm 0.1781446$ & 0.997 & 0.7943 & 6.98 \\
\hline RDW & 0.00184 & $0.26398 * *$ & 0.00277 & $0.438 \pm 0.342313$ & 0.990 & 0.4109 & 12.03 \\
\hline SFW & 0.04842 & $3.42298 * *$ & 0.01767 & $1.07 \pm 0.0949348$ & 0.995 & 1.4877 & 12.43 \\
\hline SDW & 0.00142 & $0.16786^{* *}$ & 0.00281 & $0.394 \pm 0.4299582$ & 0.983 & 0.3256 & 13.45 \\
\hline TDMP & 0.00032 & $0.73864 * *$ & 0.00398 & $0.834 \pm 0.204379$ & 0.995 & 0.6909 & 7.56 \\
\hline SR & 7.571 & $848.789 * *$ & 5.274 & $30.156 \pm 0.0060303$ & 0.994 & 23.4024 & 7.62 \\
\hline
\end{tabular}

For parameter abbreviations, see Table $2 . \mathrm{MS}(\mathrm{R})=$ mean square of replications; $\mathrm{MS}(\mathrm{V})=$ mean square of varieties; $\mathrm{MS}(\mathrm{E})=$ mean square of errors; $\mathrm{h}^{2}=$ heritability; $\mathrm{GA}=$ genetic advance; $\mathrm{CV}=$ coefficient of variability. $* *$ Highly significant.

The highest estimates of heritability were seen between 0.980 (LRL) to 0.994 (RFW) for all characters listed in Table 4. Values of genetic advance ranged between 13.89 for LA and 0.25 for SDW. CV was in the range of 5.77 to 14.54 .

The highest estimates of heritability were found between 0.977 (SR) to 0.993 (LA) for all characters listed in Table 5. Values of genetic advance ranged between 16.11 for LA and 0.32 for RDW. CV was in the range of 5.24 to 11.61 . 


\begin{tabular}{|c|c|c|c|c|c|c|c|}
\hline Parameters & $\mathrm{MS}(\mathrm{R})$ & $\operatorname{MS}(\mathrm{V})$ & MS(E) & Means $\pm \mathrm{SE}$ & $h^{2}$ & GA & $\mathrm{CV}(\%)$ \\
\hline$\overline{\mathrm{LA}}$ & 1.838 & $300.914 * *$ & 2.711 & $12.7784 \pm 0.010135$ & 0.991 & 13.8950 & 12.89 \\
\hline RV & 0.02711 & $0.98106^{* *}$ & 0.01739 & $2.1071 \pm 0.1778917$ & 0.982 & 0.7864 & 6.26 \\
\hline LRL & 7.195 & $176.143 * *$ & 3.436 & $27.3751 \pm 0.013282$ & 0.980 & 10.5183 & 6.77 \\
\hline PH & 1.535 & $128.562 * *$ & 2.602 & $27.9376 \pm 0.015549$ & 0.980 & 8.9793 & 5.77 \\
\hline RFW & 0.00098 & $0.58209 * *$ & 0.00347 & $0.6467 \pm 0.2302616$ & 0.994 & 0.6130 & 9.11 \\
\hline RDW & 0.00025 & $0.16825^{* *}$ & 0.00112 & $0.3883 \pm 0.428367$ & 0.993 & 0.3293 & 8.62 \\
\hline SFW & 0.00887 & $2.60399 * *$ & 0.01695 & $0.8953 \pm 0.1088818$ & 0.993 & 1.2958 & 14.54 \\
\hline SDW & 0.00053 & $0.10274 * *$ & 0.00208 & $0.4131 \pm 0.5500551$ & 0.980 & 0.2538 & 11.03 \\
\hline TDMP & 0.00985 & $0.31447 * *$ & 0.00597 & $0.8031 \pm 0.314304$ & 0.981 & 0.4447 & 9.62 \\
\hline SR & 9.161 & $815.416^{* *}$ & 10.875 & $46.5627 \pm 0.006163$ & 0.987 & 22.7733 & 7.08 \\
\hline
\end{tabular}

For parameter abbreviations, see Table 2 . For other abbreviations, see legend to Table 3 . **Highly significant.

Table 5. Means and analysis of variance for 10 seedling traits among 64 genotypes of Zea mays $\mathrm{L} \mathrm{T}_{3}$ (moisture level of $80 \%$ of field capacity).

\begin{tabular}{|c|c|c|c|c|c|c|c|}
\hline Parameters & MS(R) & $\mathrm{MS}(\mathrm{V})$ & MS(E) & Means $\pm \mathrm{SE}$ & $h^{2}$ & GA & CV (\%) \\
\hline LA & 2.692 & $402.774 * *$ & 2.689 & $17.358 \pm 0.0087551$ & 0.993 & 16.1134 & 9.45 \\
\hline RV & 0.01301 & $1.02351 * *$ & 0.00881 & $1.51 \pm 0.173764$ & 0.991 & 0.8103 & 6.21 \\
\hline LRL & 0.503 & $133.472 * *$ & 2.558 & $28.781 \pm 0.0152569$ & 0.981 & 9.1592 & 5.56 \\
\hline PH & 0.971 & $250.007 * *$ & 2.836 & $32.109 \pm 0.0111258$ & 0.989 & 12.6354 & 5.24 \\
\hline RFW & 0.01034 & $0.59557 * *$ & 0.00953 & $0.841 \pm 0.2282176$ & 0.984 & 0.6138 & 11.61 \\
\hline RDW & 0.00108 & $0.16881 * *$ & 0.00134 & $0.468 \pm 0.4277935$ & 0.992 & 0.3295 & 7.81 \\
\hline SFW & 0.01229 & $1.51535^{* *}$ & 0.01331 & $1.222 \pm 0.1428134$ & 0.991 & 0.9863 & 9.44 \\
\hline SDW & 0.00107 & $0.18485^{* *}$ & 0.00203 & $0.487 \pm 0.4091182$ & 0.989 & 0.3437 & 9.25 \\
\hline TDMP & 0.00861 & $0.50093 * *$ & 0.00661 & $0.94 \pm 0.2486705$ & 0.987 & 0.5645 & 8.62 \\
\hline SR & 7.911 & $661.926 * *$ & 15.520 & $69.344 \pm 0.0068584$ & 0.977 & 20.3080 & 5.68 \\
\hline
\end{tabular}

For parameter abbreviations, see Table 2. For other abbreviations, see legend to Table 3. **Highly significant.

The highest estimates of heritability were seen between 0.994 (LA) to 0.943 (SR) for all characters listed in Table 6. Values of genetic advance ranged between 18.90 for SR and 0.36 for SDW. CV was in the range of 6.55 to 11.71 . The higher heritability values indicated that selection could be made on the basis of these traits (Dasgupta et al., 1992). The higher values of genotypic coefficient of variance showed that these traits could be used for selecting higher yielding maize genotypes. The same results were reported by Ojo et al. (2006).

Table 6. Means and analysis of variance for 10 seedling traits among 64 genotypes of Zea mays L. T (moisture $_{4}$ level of $100 \%$ of field capacity).

\begin{tabular}{|c|c|c|c|c|c|c|c|}
\hline Parameters & MS(R) & MS(V) & MS(E) & Means $\pm \mathrm{SE}$ & $h^{2}$ & GA & $\mathrm{CV}(\%)$ \\
\hline LA & 0.805 & $520.953 * *$ & 3.335 & $17.706 \pm 0.0076978$ & 0.994 & 18.3306 & 10.31 \\
\hline RV & 0.00782 & $1.04501^{* *}$ & 0.01245 & $1.468 \pm 0.17211$ & 0.988 & 0.8164 & 7.60 \\
\hline LRL & 9.0319 & $99.2256 * *$ & 4.8829 & $28.813 \pm 0.0178281$ & 0.951 & 7.6553 & 7.67 \\
\hline PH & 12.706 & $239.163 * *$ & 7.717 & $36.073 \pm 0.0114351$ & 0.968 & 12.0969 & 7.70 \\
\hline RFW & 0.1521 & $1.07336 * *$ & 0.00837 & $0.861 \pm 0.1696455$ & 0.992 & 0.8309 & 10.62 \\
\hline RDW & 0.00042 & $0.41529 * *$ & 0.00382 & $0.528 \pm 0.2728325$ & 0.991 & 0.5161 & 11.71 \\
\hline SFW & 0.01412 & $1.71775^{* *}$ & 0.01015 & $1.244 \pm 0.1340385$ & 0.994 & 1.0531 & 8.10 \\
\hline SDW & 0.00154 & $0.20798 * *$ & 0.00260 & $0.564 \pm 0.3858505$ & 0.987 & 0.3640 & 9.04 \\
\hline TDMP & 0.01448 & $0.96068 * *$ & 0.01109 & $1.089 \pm 0.1794888$ & 0.988 & 0.7831 & 9.67 \\
\hline SR & 14.164 & $615.584 * *$ & 35.383 & $90.802 \pm 0.0071724$ & 0.943 & 18.9018 & 6.55 \\
\hline
\end{tabular}

For parameter abbreviations, see Table 2. For other abbreviations, see legend to Table 3. **Highly significant.

\section{Genotypic and phenotypic correlation}

The correlation studies were carried out with the objective of observing a mutual re- 
lationship between various characters and also the type and extent of the contribution to yield (Panhwar et al., 2003; Chaudhary and Joshi, 2005). Genotypic and phenotypic correlations were observed between ten characters under four different moisture levels and are presented in Tables 7 to 10, respectively.

Table 7. Genotypic $\left(r_{\mathrm{g}}\right)$ and phenotypic $\left(\mathrm{r}_{\mathrm{p}}\right)$ correlation under $\mathrm{T}_{1}$ (moisture level of $40 \%$ of field capacity).

\begin{tabular}{|c|c|c|c|c|c|c|c|c|c|c|}
\hline Traits & LA & $\mathrm{RV}$ & LRL & $\mathrm{PH}$ & RFW & RDW & SFW & SDW & TDMP & SR \\
\hline \multicolumn{11}{|l|}{$\mathrm{LA}$} \\
\hline $\begin{array}{l}r_{g} \\
r_{p}\end{array}$ & 1 & $\begin{array}{l}0.4137^{*} \\
0.4116^{* *}\end{array}$ & $\begin{array}{l}0.6442^{*} \\
0.6348^{* *}\end{array}$ & $\begin{array}{l}0.7206^{*} \\
0.7147^{* *}\end{array}$ & $\begin{array}{l}0.6364^{*} \\
0.7336^{* *}\end{array}$ & $\begin{array}{l}0.6475^{*} \\
0.6435^{* *}\end{array}$ & $\begin{array}{l}0.8223 * \\
0.8198^{* *}\end{array}$ & $\begin{array}{l}0.7515^{*} \\
0.7432^{* *}\end{array}$ & $\begin{array}{l}0.7374 * \\
0.7331^{* *}\end{array}$ & $\begin{array}{l}0.4885^{*} \\
0.4866^{* * *}\end{array}$ \\
\hline $\mathrm{RV}^{\mathrm{p}}$ & & & & & & & & & & \\
\hline $\begin{array}{r}r_{g} \\
r_{p} \\
L R L\end{array}$ & & 1 & $\begin{array}{l}0.2796^{*} \\
0.2785^{* *}\end{array}$ & $\begin{array}{l}0.2267 * \\
0.2256^{* *}\end{array}$ & $\begin{array}{l}0.4570^{*} \\
0.4549^{* *}\end{array}$ & $\begin{array}{l}0.4621^{*} \\
0.4589^{* *}\end{array}$ & $\begin{array}{l}0.4943 * \\
0.4907 * *\end{array}$ & $\begin{array}{l}0.4850^{*} \\
0.4791^{* *}\end{array}$ & $\begin{array}{l}0.5005^{*} \\
0.4992^{* *}\end{array}$ & $\begin{array}{l}0.1908^{*} \\
0.1896^{* * *}\end{array}$ \\
\hline $\begin{array}{l}r_{g} \\
r_{p}\end{array}$ & & & 1 & $\begin{array}{l}0.6580^{*} \\
0.6505^{* *}\end{array}$ & $\begin{array}{l}0.5722^{*} \\
0.5674 * *\end{array}$ & $\begin{array}{l}0.4606^{*} \\
0.4528^{* *}\end{array}$ & $\begin{array}{l}0.5675^{*} \\
0.5589^{* *}\end{array}$ & $\begin{array}{l}0.5183^{*} \\
0.5124^{*} *\end{array}$ & $\begin{array}{l}0.5163^{*} \\
0.5123^{* *}\end{array}$ & $\begin{array}{l}0.4471 * \\
0.4415^{* *}\end{array}$ \\
\hline $\mathrm{PH}^{\mathrm{p}}$ & & & & & & & & & & \\
\hline $\begin{array}{c}r_{g} \\
r_{p} \\
R F W\end{array}$ & & & & 1 & $\begin{array}{l}0.5719^{*} \\
0.5680^{* *}\end{array}$ & $\begin{array}{l}0.4493^{*} \\
0.4458^{* * *}\end{array}$ & $\begin{array}{l}0.7154^{*} \\
0.7105^{* *}\end{array}$ & $\begin{array}{l}0.7216^{*} \\
0.7112^{* *}\end{array}$ & $\begin{array}{l}0.6124 * \\
0.6071 * *\end{array}$ & $\begin{array}{l}0.4169^{*} \\
0.4130^{* *}\end{array}$ \\
\hline $\mathrm{r}_{\mathrm{g}}$ & & & & & 1 & $\begin{array}{l}0.8356^{*} \\
0.8313^{* *}\end{array}$ & $\begin{array}{l}0.8181^{*} \\
0.8156^{* *}\end{array}$ & $\begin{array}{l}0.7685^{*} \\
0.7620^{* *}\end{array}$ & $\begin{array}{l}0.8658^{*} \\
0.8620^{* *}\end{array}$ & $\begin{array}{l}0.5347 * \\
0.5330^{* *}\end{array}$ \\
\hline RDW & & & & & & & & & & \\
\hline $\begin{array}{c}r_{g} \\
r_{p} \\
S F W\end{array}$ & & & & & & 1 & $\begin{array}{l}0.6776^{*} \\
0.6747^{* *}\end{array}$ & $\begin{array}{l}0.7176^{*} \\
0.7028^{* *}\end{array}$ & $\begin{array}{l}0.9479 * \\
0.9395^{* *}\end{array}$ & $\begin{array}{l}0.3869^{*} \\
0.3850^{* *}\end{array}$ \\
\hline $\begin{array}{c}\mathrm{r}_{\mathrm{g}} \\
\mathrm{r}_{\mathrm{p}}\end{array}$ & & & & & & & 1 & $\begin{array}{l}0.9128^{*} \\
0.9027^{* *}\end{array}$ & $\begin{array}{l}0.8400^{*} \\
0.8346^{* *}\end{array}$ & $\begin{array}{l}0.3846 * \\
0.3838 \text { ** }\end{array}$ \\
\hline $\begin{array}{l}\text { SDW } \\
r_{\mathrm{g}} \\
\mathrm{r}_{\mathrm{p}} \\
\mathrm{TDMP}\end{array}$ & & & & & & & & 1 & $\begin{array}{l}0.9120^{*} \\
0.9012^{* *}\end{array}$ & $\begin{array}{l}0.4617 * \\
0.4562 * *\end{array}$ \\
\hline $\begin{array}{l}r_{g} \\
r_{p} \\
r^{p}\end{array}$ & & & & & & & & & 1 & $\begin{array}{l}0.4450^{*} \\
0.4432 * *\end{array}$ \\
\hline $\begin{array}{r}\mathrm{SR}^{R} \\
\mathrm{r}_{\mathrm{g}} \\
\mathrm{r}_{\mathrm{p}}\end{array}$ & & & & & & & & & & 1 \\
\hline
\end{tabular}

For parameter abbreviations, see Table 2. *Significant results. **Highly significant.

Table 7 shows the positive and significant genotypic correlation observed between the pairs of traits, e.g., RV with LA and positive and highly significant phenotypic correlation was observed between the pairs of traits e.g. RV and LA. Genotypically, LRL was significantly and positively correlated with LA and RV, while phenotypically, these were positively and highly significantly correlated. Genotypically, PH was significantly and positively correlated with LA, RV and LRL, while phenotypically, PH was positively and highly significantly correlated with LA, RV and LRL. Genotypically, RFW was significantly and positively correlated with LA, RV, LRL and PH, while phenotypically, RFW was positively and highly significantly correlated with LA, RV, LRL and PH. Genotypically, RDW was significantly and positively correlated with LA, RV, LRL, PH and RFW, while phenotypically, RDW was positively and highly significantly correlated with LA, RV, LRL, PH and RFW. Genotypically, SFW was significantly and positively correlated with LA, RV, LRL, PH, RFW and RDW, while phenotypically, RDW was positively and highly significantly correlated with LA, RV, LRL, PH, RFW and RDW. Genotypically, SDW was significantly and positively correlated with LA, RV, LRL, PH, RFW, RDW and SFW, while phenotypically, SDW was positively and highly 
significantly correlated with LA, RV, LRL, PH, RFW, RDW and SFW. Genotypically, TDMP was significantly and positively correlated with LA, RV, LRL, PH, RFW, RDW and SFW and SDW, while phenotypically, TDMP was positively and highly significantly correlated with LA, RV, LRL, PH, RFW, RDW, SFW and SDW. Genotypically, SR was significantly and positively correlated with LA, RV, LRL, PH, RFW, RDW, SFW, SDW and TDMP, while phenotypically, SR was positively and highly significantly correlated with LA, RV, LRL, PH, RFW, RDW, SFW, SDW and TDMP.

With respect to Table 8, a positive and significant genotypic correlation was observed between the pairs of traits e.g. RV with LA and positive and significant phenotypic correlation was observed between the pairs of traits e.g. RV and LA. Genotypically, LRL was significantly and positively correlated with LA and not significantly with RV, while phenotypically, LRL was positively and highly significantly correlated with LA but not significantly with RV. Genotypically, PH was significantly and positively correlated with LA, RV and LRL, while phenotypically, PH was positively and highly significantly correlated with LA, RV and LRL. Genotypically RFW was significantly and positively correlated with LA, LRL and PH but not significantly with RV, whereas phenotypically, RFW was positively and highly significantly correlated with LA, LRL and PH but not significantly with RV. Genotypically, RDW was significantly and positively correlated with LA, LRL, PH and RFW but not significantly with $\mathrm{RV}$, whereas phenotypically, RDW was positively and highly significantly correlated with LA, LRL, PH and RFW but not significantly with RV. Genotypically, SFW was significantly and positively correlated with LA, LRL, PH, RFW and RDW but not significantly with RV, while phenotypically, RDW was positively and highly significantly correlated with LA, RV, LRL, PH, RFW and RDW. Genotypically, SDW was significantly and positively correlated with LA, PH, and SFW but not significantly with RV, LRL, RFW and RDW, whereas phenotypically, SDW was positively and highly significantly correlated with LA, RV, PH, RFW and SFW but significantly with RDW and not significantly with LRL. Genotypically, TDMP was significantly and positively correlated with LA, LRL, PH, RFW, RDW and SFW and SDW but not significantly with RV, whereas phenotypically, TDMP was positively and highly significantly correlated with LA, RV, LRL, PH, RFW, RDW, SFW and SDW. Genotypically, SR was significantly and positively correlated with LA, RV, LRL, PH, RFW, RDW, SFW, SDW and TDMP, but phenotypically, SR was positively and highly significantly correlated with LA, RV, LRL, PH, RFW, RDW, SFW and TDMP but not significantly with SDW.

In connection with Table 9, a negative and non-significant genotypic correlation was observed between the pairs of traits e.g. RV with LA and negative and non significant phenotypic correlation was observed between the pairs of traits e.g. RV and LA. Genotypically, LRL was not significantly and negatively correlated with LA and not significantly but negatively correlated with RV, while phenotypically, LRL was negatively and highly significantly correlated with LA but not significantly and positively correlated with RV. Genotypically, PH was significantly and positively correlated with LA, while not significantly and negatively correlated with RV and LRL, while phenotypically, PH was positively and highly significantly correlated with LA but not significantly and negatively correlated with RV, but significantly and negatively correlated with LRL. Genotypically, RFW was significant and positively correlated with LA and PH but not significantly and negatively correlated with RV and LRL, while phenotypically, RFW was positively and highly significantly with LA and PH but negatively correlated with RV and LRL. Genotypically, RDW was significantly and positively 
correlated with LA, PH and RFW while not significantly and negatively correlated with RV and LRL, while phenotypically, RDW was positively and highly significantly correlated with $\mathrm{PH}$ and RFW but significantly with LA and not significantly and negatively correlated with RV. Genotypically, SFW was significantly and positively correlated with LA, PH, RFW and RDW but not significantly with RV and significantly and negatively correlated with LRL; phenotypically, SFW was positively and highly significantly with LA, PH, RFW and RDW but negatively correlated with LRL and not significantly and positively correlated with RV. Genotypically. SDW was significantly and positively correlated with LA, PH, RFW and SFW but not significantly with RV and RDW and not significantly and negatively correlated with LRL; phenotypically, SDW was positively and highly significantly correlated with LA, PH, RFW, RDW and SFW but negatively correlated with LRL and not significantly but positively correlated with RV. Genotypically, TDMP was significantly and positively correlated with LA, PH, RFW, RDW and SFW and SDW but not significantly with RV and negatively correlated with LRL; phenotypically, TDMP was positively and highly significantly correlated with LA, RFW, RDW, SFW and SDW but negatively correlated with LRL but not significantly and positively correlated with RV and PH. Genotypically, SR was significantly and positively correlated with LA, RV, RFW, SFW, SDW and TDMP but not significantly with LRL and RFW, while phenotypically, SR was positively and highly significantly correlated with LA, RV, RFW, RDW, SFW and significantly with SDW but not significantly with LRL, PH and RDW.

Table 8. Genotypic $\left(r_{g}\right)$ and phenotypic $\left(r_{p}\right)$ correlation under $T_{2}$ (moisture level of $60 \%$ of field capacity).

\begin{tabular}{|c|c|c|c|c|c|c|c|c|c|c|}
\hline Traits & LA & $\mathrm{RV}$ & LRL & $\mathrm{PH}$ & RFW & RDW & SFW & SDW & TDMP & SR \\
\hline \multicolumn{11}{|l|}{ LA } \\
\hline$r_{g}$ & 1 & $0.1831^{*}$ & $0.2822 *$ & $0.7464 *$ & $0.5573^{*}$ & $0.3545^{*}$ & $0.8832 *$ & $0.3754^{*}$ & $0.4687^{*}$ & $0.3204 *$ \\
\hline \multicolumn{11}{|l|}{$\mathrm{RV}^{\mathrm{D}}$} \\
\hline$r_{g}$ & & 1 & 0.0358 & $0.2475^{*}$ & 0.0287 & 0.1371 & 0.1595 & 0.2604 & 0.2417 & $0.2205^{*}$ \\
\hline$r_{p}^{g}$ & & & 0.0340 & $0.2403 * *$ & 0.0270 & 0.1367 & $0.1564^{*}$ & $0.2539 * *$ & $0.2372 * *$ & $0.2165^{* *}$ \\
\hline \multicolumn{11}{|l|}{ LRL } \\
\hline$r_{g}$ & & & 1 & $0.2756^{*}$ & $0.3601^{*}$ & $0.3453^{*}$ & $0.4039^{*}$ & 0.0659 & $0.2916^{*}$ & $0.3207^{*}$ \\
\hline$r_{p}$ & & & & $0.2761^{* *}$ & $0.3542^{* *}$ & $0.3418^{* *}$ & $0.3971^{* *}$ & 0.0597 & $0.2866^{* *}$ & $0.3164 * *$ \\
\hline \multicolumn{11}{|l|}{$\mathrm{PH}^{\mathrm{p}}$} \\
\hline$r_{g}$ & & & & 1 & $0.5187^{*}$ & $0.4089 *$ & $0.7019^{*}$ & $0.3956^{*}$ & $0.5259^{*}$ & $0.3707^{*}$ \\
\hline \multicolumn{11}{|l|}{ RFW } \\
\hline$r_{g}$ & & & & & 1 & $0.6809^{*}$ & $0.6383 *$ & 0.3115 & $0.6820^{*}$ & $0.2265^{*}$ \\
\hline \multirow{2}{*}{\multicolumn{11}{|c|}{ RDW }} \\
\hline & & & & & & & & & & \\
\hline$r_{g}$ & & & & & & 1 & $0.4224^{*}$ & 0.1699 & $0.8439^{*}$ & $0.3316^{*}$ \\
\hline \multicolumn{11}{|l|}{ SFW } \\
\hline$r_{g}$ & & & & & & & 1 & $0.4767^{*}$ & $0.5837^{*}$ & $0.3711 *$ \\
\hline$r_{p}^{g}$ & & & & & & & & $0.4713 * *$ & $0.5741 * *$ & $0.3669^{* *}$ \\
\hline \multicolumn{11}{|l|}{ SDW } \\
\hline$r_{g}$ & & & & & & & & 1 & $0.6938^{*}$ & $0.1209^{*}$ \\
\hline \multirow{2}{*}{\multicolumn{11}{|c|}{ TDMP }} \\
\hline & & & & & & & & & & \\
\hline$r_{g}$ & & & & & & & & & 1 & $0.3090^{*}$ \\
\hline \multirow{2}{*}{\multicolumn{11}{|c|}{$\mathrm{SR}^{\mathrm{p}}$}} \\
\hline & & & & & & & & & & \\
\hline $\mathrm{r}_{\mathrm{g}}$ & & & & & & & & & & 1 \\
\hline
\end{tabular}

For parameter abbreviations, see Table $2 .{ }^{*}$ Significant results. ${ }^{* *}$ Highly significant. 
Table 9. Genotypic $\left(r_{g}\right)$ and phenotypic $\left(r_{p}\right)$ correlation under $\mathrm{T}_{3}$ (moisture level of $80 \%$ of field capacity).

\begin{tabular}{|c|c|c|c|c|c|c|c|c|c|c|}
\hline Traits & LA & RV & LRL & $\mathrm{PH}$ & RFW & RDW & SFW & SDW & TDMP & SR \\
\hline \multicolumn{11}{|l|}{ LA } \\
\hline$r_{g}$ & 1 & -0.0472 & -0.2091 & $0.4616^{*}$ & $0.4796 *$ & $0.1850^{*}$ & $0.6618 *$ & $0.3822 *$ & $0.2724 *$ & $0.3180^{*}$ \\
\hline \multicolumn{11}{|l|}{$\mathrm{RV}^{\mathrm{p}}$} \\
\hline$r_{g}$ & & 1 & 0.0200 & -0.0041 & -0.0272 & -0.0746 & 0.0629 & 0.1109 & 0.0112 & $0.3391^{*}$ \\
\hline$r_{p}^{g}$ & & & 0.0199 & -0.0040 & -0.0265 & -0.0757 & 0.0625 & 0.1109 & 0.0124 & $0.3330^{* *}$ \\
\hline \multicolumn{11}{|l|}{ LRL } \\
\hline$r_{g}$ & & & 1 & -0.1823 & -0.2520 & -0.2759 & -0.2797 & -0.2781 & -0.3074 & 0.0033 \\
\hline$r_{p}^{g}$ & & & & $-0.1779^{*}$ & $-0.2426^{* *}$ & $-0.2706^{* *}$ & $-0.2752 * *$ & $-0.2733 * *$ & $-0.3018 * *$ & 0.0056 \\
\hline \multicolumn{11}{|c|}{0.2100} \\
\hline$r_{g}$ & & & & 1 & $0.3424 *$ & $0.2783^{*}$ & $0.7445^{*}$ & $0.5035^{*}$ & $0.4316^{*}$ & $0.0778^{*}$ \\
\hline$r^{g}$ & & & & & $0.3370^{* *}$ & $0.2766^{* *}$ & $0.7367^{* *}$ & $0.4996 * *$ & 0.4282 & 0.0767 \\
\hline \multicolumn{11}{|l|}{ RFW } \\
\hline$r_{g}$ & & & & & 1 & $0.7039^{*}$ & $0.5202^{*}$ & $0.4063^{*}$ & $0.6468 *$ & $0.2098^{*}$ \\
\hline \multicolumn{11}{|l|}{$\mathrm{RDW}$} \\
\hline$r_{g}$ & & & & & & 1 & $0.3488^{*}$ & 0.4616 & $0.8629 *$ & 0.0562 \\
\hline$r_{p}^{g}$ & & & & & & & $0.3477^{* *}$ & $0.4572 * *$ & $0.8526 * *$ & 0.0572 \\
\hline \multicolumn{11}{|l|}{ SFW } \\
\hline$r_{g}$ & & & & & & & 1 & $0.6429^{*}$ & $0.5766^{*}$ & $0.2057^{*}$ \\
\hline \multicolumn{8}{|l|}{ SDW } & $0.6399 * *$ & $0.5687^{* *}$ & $0.2006^{* *}$ \\
\hline$r_{g}$ & & & & & & & & 1 & $0.7885^{*}$ & $0.1844 *$ \\
\hline$r_{p}^{g}$ & & & & & & & & & $0.7777 * *$ & $0.1794 *$ \\
\hline \multicolumn{11}{|l|}{ TDMP } \\
\hline$r_{g}$ & & & & & & & & & 1 & $0.0975^{*}$ \\
\hline \multirow{2}{*}{\multicolumn{10}{|c|}{$\mathrm{SR}^{\mathrm{p}}$}} & 0.0948 \\
\hline $\begin{array}{r}\mathrm{SK} \\
\mathrm{r}_{\mathrm{g}}\end{array}$ & & & & & & & & & & 1 \\
\hline $\begin{array}{l}\mathrm{g} \\
\mathrm{r}_{\mathrm{p}} \\
\mathrm{p}\end{array}$ & & & & & & & & & & \\
\hline
\end{tabular}

For parameter abbreviations, see Table $2 .{ }^{*}$ Significant results. **Highly significant.

Regarding the Table 10, a negative and non significant genotypic correlation was observed between the pairs of traits e.g. RV with LA and negative and non significant phenotypic correlation was observed between the pairs of traits e.g. RV and LA. Genotypically, LRL was significantly and positively correlated with RV but not significantly and negatively correlated with LA, while phenotypically, it was positively and highly significantly correlated with RV but not significantly and negatively correlated with LA. Genotypically, PH was significantly and positively correlated with LA, and not significantly with LRL but not significantly and negatively correlated with RV, whereas phenotypically, PH was positively and highly significantly correlated with LA but not significant with LRL and not significantly and negatively correlated with RV. Similar results were reported by Malik et al. (2005) and Ojo et al. (2006). Genotypically, RFW was significantly and positively correlated with LA and PH but not significantly and negatively correlated with RV and LRL, whereas phenotypically, RFW was positively and highly significantly correlated with PH but not significantly with LA and not significantly and negatively correlated with RV and LRL. Genotypically, RDW was significantly and positively correlated with PH and RFW but not significantly and negatively correlated with LA, RV and LRL, whereas phenotypically, RDW was positively and highly significantly with $\mathrm{PH}$ and RFW but not significantly and negatively correlated with LA, RV and LRL. Genotypically, SFW was significantly and positively correlated with LA, PH, RFW and RDW but not significantly and negatively correlated with RV and LRL, while phenotypically, SFW was positively and highly significantly correlated with LA, PH, 
RFW and RDW but not significantly and negatively correlated with RV and LRL. Genotypically, SDW was significantly and positively correlated with LA, PH, RFW, RDW and SFW but not significantly and negatively correlated with RV and LRL, whereas phenotypically, SDW was positively and highly significantly correlated with LA, PH, RFW, RDW and SFW but not significantly and negatively correlated with RV and LRL. Genotypically, TDMP was significantly and positively correlated with LA, PH, RFW, RDW and SFW and SDW but not significantly and negatively correlated with RV and LRL while phenotypically, TDMP was positively and highly significantly correlated with LA, PH, RFW, RDW, SFW and SDW but not significantly and negatively correlated with RV and LRL. Genotypically, SR was significantly and positively correlated with LA, RV, LRL, PH, RFW, RDW, SFW, SDW and TDMP, while phenotypically, SR was positively and highly significantly correlated with LA, RV, PH, RFW, RDW, SFW, SDW and TDMP but not significantly and positively correlated with LRL.

Table 10. Genotypic $\left(\mathrm{r}_{\mathrm{g}}\right)$ and phenotypic $\left(\mathrm{r}_{\mathrm{p}}\right)$ correlation under $\mathrm{T}_{4}$ (moisture level of $100 \%$ of field capacity).

\begin{tabular}{|c|c|c|c|c|c|c|c|c|c|c|}
\hline Traits & LA & RV & LRL & PH & RFW & RDW & SFW & SDW & TDMP & SR \\
\hline \multicolumn{11}{|l|}{ LA } \\
\hline$r_{g}$ & 1 & -0.0255 & -0.0421 & $0.5173^{*}$ & $0.1335^{*}$ & -0.0175 & $0.6390^{*}$ & $0.5005^{*}$ & $0.2241 *$ & $0.1922^{*}$ \\
\hline$r_{p}^{g}$ & & -0.0242 & -0.0408 & $0.5091^{* *}$ & 0.1330 & -0.0181 & $0.6352 * *$ & $0.4968 * *$ & $0.2233^{* *}$ & $0.1862 * *$ \\
\hline \multicolumn{11}{|l|}{$R V^{p}$} \\
\hline$r_{g}$ & & 1 & $0.3763^{*}$ & -0.0160 & -0.0937 & -0.0907 & -0.0943 & -0.0391 & -0.0833 & $0.2473^{*}$ \\
\hline & & & $0.3660 * *$ & -0.0158 & -0.0798 & -0.0909 & -0.0926 & -0.0363 & -0.0823 & $0.2365 * *$ \\
\hline \multicolumn{11}{|l|}{ LRL } \\
\hline$r_{g}$ & & & 1 & 0.0135 & -0.0833 & -0.0722 & -0.0510 & -0.0362 & -0.0665 & $0.0318^{*}$ \\
\hline$r_{p}^{g}$ & & & & 0.0107 & -0.0798 & -0.0709 & -0.0506 & -0.0334 & -0.0658 & 0.0252 \\
\hline \multicolumn{11}{|l|}{$\mathrm{PH}$} \\
\hline$r_{g}$ & & & & 1 & $0.3255^{*}$ & $0.2038^{*}$ & $0.6683^{*}$ & $0.6945^{*}$ & $0.4542 *$ & $0.3482^{*}$ \\
\hline$r_{p}^{g}$ & & & & & $0.3183^{* *}$ & $0.1998 * *$ & $0.6554 * *$ & $0.6777 * *$ & $0.4471 * *$ & $0.3438^{* *}$ \\
\hline \multicolumn{11}{|l|}{ RFW } \\
\hline $\mathrm{r}_{\mathrm{g}}$ & & & & & 1 & $0.9268^{*}$ & $0.4912 *$ & $0.5888^{*}$ & $0.8886^{*}$ & $0.3020^{*}$ \\
\hline$r_{p}^{s}$ & & & & & & $0.9200 * *$ & $0.4872^{* *}$ & $0.5827 * *$ & $0.8817 * *$ & $0.2900 * *$ \\
\hline \multicolumn{11}{|l|}{ RDW } \\
\hline $\mathrm{r}_{\mathrm{g}}$ & & & & & & 1 & $0.3567^{*}$ & $0.5624 *$ & $0.9324 *$ & $0.2293^{*}$ \\
\hline$r_{p}^{g}$ & & & & & & & $0.3531 * *$ & $0.5533 * *$ & $0.9203^{* *}$ & $0.2184 * *$ \\
\hline \multicolumn{11}{|l|}{ SFW } \\
\hline $\mathrm{r}_{\mathrm{g}}$ & & & & & & & 1 & $0.8097^{*}$ & $0.6167^{*}$ & $0.2920^{*}$ \\
\hline$r_{p}^{g}$ & & & & & & & & $0.8034 * *$ & $0.6119 * *$ & $0.2838 * *$ \\
\hline \multicolumn{11}{|l|}{ SDW } \\
\hline$r_{g}$ & & & & & & & & 1 & $0.8419 *$ & $0.2602^{*}$ \\
\hline $\mathrm{r}_{\mathrm{p}}$ & & & & & & & & & $0.8330 * *$ & $0.2487 * *$ \\
\hline \multicolumn{11}{|l|}{ TDMP } \\
\hline$r_{g}$ & & & & & & & & & 1 & $0.2751^{*}$ \\
\hline$r_{p}^{g}$ & & & & & & & & & & $0.2678^{* *}$ \\
\hline \multicolumn{11}{|l|}{$\mathrm{SR}^{\mathrm{p}}$} \\
\hline$r_{g}$ & & & & & & & & & & 1 \\
\hline$r_{p}$ & & & & & & & & & & \\
\hline
\end{tabular}

For parameter abbreviations, see Table $2 .{ }^{*}$ Significant results. **Highly significant.

\section{PC analysis}

The first two, four, three and again three components, with eigenvalues $>1$ contributed $75.05,80.11,68.67$ and $75.87 \%$ (Tables 11 to 14 ) of the variability betweem the genotypes under the different moisture levels, i.e., $\mathrm{T}_{1} 40 \%, \mathrm{~T}_{2} 60 \% \mathrm{~T}_{3} 80 \%$ and $\mathrm{T}_{4} 100 \%$, respectively, and evaluated for seedling components (Table 2). Other PC's (3-10, 5-10, 4-10 and again 4-10) had eigenvalues less than 1 . 
Table 11. Principle component analysis (PC) under $T_{1}$ (moisture level of $40 \%$ of field capacity).

\begin{tabular}{lcc}
\hline & PC1 & PC2 \\
\hline Eigen-values & 6.490241 & 1.015743 \\
Proportion of variance & 64.90241 & 10.15743 \\
Cumulative variance & 64.9024 & 75.0598 \\
\hline & & Eigen vectors \\
\cline { 2 - 3 } & PC1 & PC2 \\
\hline Variables & & \\
LA & -0.873293 & -0.149170 \\
RV & -0.542246 & 0.557266 \\
LRL & -0.691974 & -0.434495 \\
PH & -0.761610 & -0.416726 \\
RFW & -0.902532 & 0.096830 \\
RDW & -0.832289 & 0.309597 \\
SFW & -0.915947 & 0.055735 \\
SDW & -0.911815 & 0.071785 \\
TDMP & -0.933759 & 0.224974 \\
SR & -0.570222 & -0.395474 \\
\hline
\end{tabular}

For parameter abbreviations, see Table 2.

Tables 11 to 14 , PCs for 10 seedling characters in 64 genotypes of maize.

The first PC (PC1) was not related to any character, whereas the second PC was related to RWF, RDW, SFW, SDW and TDMP, in PC2; RV exhibited the greatest positive weight as shown in Table 11. The first two PCs contributed to $75.09 \%$ of the variability.

The first $\mathrm{PC}$ (PC1) was not related to any attribute, whereas the second $\mathrm{PC}$ was related to RV, SDW, PH, LA, TDMP and SFW. The third PC exhibited positive effects for TDMP, RDW, SDW and RFW. The fourth PC was more related to LA, SFW, RFW, PH and SDW, in PC2; RV exhibited the greatest positive weight as shown in Table 12. Six characters contributed positively to PC2: thus, this component was the weighted average of the characters. The first two PCs contributed to $59.02 \%$ of the variability.

Table 12. Principle component analysis (PC) under $\mathrm{T}_{2}$ (moisture level of $60 \%$ of field capacity).

\begin{tabular}{lcccc}
\hline & PC1 & PC2 & PC3 & PC4 \\
\hline Eigen-values & 4.704864 & 1.197605 & 1.091991 & 1.016592 \\
Proportion of variance & 47.04864 & 11.97605 & 10.91991 & 10.16592 \\
Cumulative variance & 47.0486 & 59.0247 & 69.9446 & 80.1105 \\
\hline \multicolumn{4}{r}{} & \multicolumn{2}{c}{ Eigen vectors } \\
\cline { 2 - 5 } & PC1 & PC2 & PC3 \\
\hline Variables & & & \\
LA & -0.796712 & 0.113853 & -0.354190 & 0.339935 \\
RV & -0.284263 & 0.597113 & -0.124278 & -0.597879 \\
LRL & -0.471477 & -0.512094 & -0.263266 & -0.200991 \\
PH & -0.785117 & 0.143827 & -0.276869 & 0.155554 \\
RFW & -0.784215 & -0.284813 & 0.245130 & 0.155658 \\
RDW & -0.716142 & -0.354990 & 0.420017 & -0.280576 \\
SFW & -0.864543 & 0.048553 & -0.249448 & 0.284155 \\
SDW & -0.567549 & 0.564265 & 0.310683 & 0.121514 \\
TDMP & -0.846001 & 0.050363 & 0.484058 & -0.135291 \\
SR & -0.487335 & -0.121434 & -0.419006 & -0.512071 \\
\hline Fory & & & & \\
\hline
\end{tabular}

For parameter abbreviations, see Table 2. 
The first PC (PC1) was more related to TDMP, SFW, SDW, RFW, RDW, PH, LA, SR and RV, whereas the second PC was related to SR, RV, LA, SFW, LRL, PH and SDW. The third PC exhibited positive effects for PH, LA and SFW, in PC1; TDMP exhibited the greatest positive weight as shown in Table 13. Nine characters contributed positively to $\mathrm{PC} 1$ : thus, this component was the weighted average of the characters. The variations for SFW, PH and LA were distributed among all the components. The first two PCs contributed to $56.94 \%$ of the variability.

\begin{tabular}{|c|c|c|c|}
\hline & PC1 & $\mathrm{PC} 2$ & $\mathrm{PC} 3$ \\
\hline Eigen-values & 4.253576 & 1.441105 & 1.173169 \\
\hline Proportion of variance & 42.53576 & 14.41105 & 11.73169 \\
\hline \multirow[t]{3}{*}{ Cumulative variance } & 42.5358 & 56.9468 & 68.6785 \\
\hline & \multicolumn{3}{|c|}{ Eigen vectors } \\
\hline & PC1 & PC2 & $\mathrm{PC} 3$ \\
\hline \multicolumn{4}{|l|}{ Variables } \\
\hline LA & 0.629044 & 0.371695 & 0.409769 \\
\hline $\mathrm{RV}$ & 0.037574 & 0.610615 & -0.564008 \\
\hline LRL & -0.409554 & 0.192749 & -0.037165 \\
\hline $\mathrm{PH}$ & 0.680725 & 0.171885 & 0.435049 \\
\hline RFW & 0.759548 & -0.146584 & -0.173924 \\
\hline RDW & 0.719095 & -0.461881 & -0.385500 \\
\hline SFW & 0.834727 & 0.243681 & 0.318564 \\
\hline SDW & 0.791693 & 0.034090 & -0.076361 \\
\hline TDMP & 0.860185 & -0.303911 & -0.293210 \\
\hline SR & 0.260518 & 0.689693 & -0.352644 \\
\hline
\end{tabular}

For parameter abbreviations, see Table 2 .

The first PC (PC1) was more related to TDMP, SDW, RFW, SFW, RDW, PH, LA and SR, whereas the second PC was related to LA, PH, SFW, RV, LRL, SR and SDW. The third PC exhibited positive effects for LA, SFW, PH and SDW in PC1; TDMP exhibited the greatest positive weight as shown in Table 14. Eight characters contributed positively to PC1: thus, this component was the weighted average of the characters. The variations for SFW, SDW, PH and LA were distributed among all the components. The first two PCs contributed to $61.63 \%$ of the variability.

Table 14. Principle component analysis (PCs) under $\mathrm{T}_{4}$ (moisture level of $100 \%$ of field capacity).

\begin{tabular}{lccc}
\hline & PC1 & PC2 & PC3 \\
\hline Eigen-values & 4.471156 & 1.692706 & 1.423213 \\
Proportion of variance & 44.71156 & 16.92706 & 14.23213 \\
Cumulative variance & 44.7116 & 61.6386 & 75.8707 \\
\hline & & Eigen vectors & PC3 \\
\cline { 2 - 4 } & PC1 & PC2 & \\
\hline Variables & & & 0.267743 \\
LA & 0.489506 & 0.656166 & -0.790388 \\
RV & -0.081978 & 0.291300 & -0.685723 \\
LRL & -0.081859 & 0.242453 & 0.078448 \\
PH & 0.681228 & 0.486335 & -0.137658 \\
RFW & 0.821183 & -0.457395 & -0.179066 \\
RDW & 0.756204 & -0.603581 & 0.172372 \\
SFW & 0.819179 & 0.358933 & 0.052808 \\
SDW & 0.903691 & 0.155924 & -0.090689 \\
TDMP & 0.924479 & -0.326258 & -0.398377 \\
SR & 0.406804 & 0.221091 & \\
\hline For & & & \\
\end{tabular}

For parameter abbreviations, see Table 2. 


\section{Cluster analysis}

V1 to V64 correspond to genotypes as in Table 1. Matrices (10 X 64) exhibited the dendrogram as shown in Figures 1 to 4 . The $35.8 \%$ level of similarity was only indicated by V61, which showed total dissimilarity to the rest of the genotypes. V38 and V62 showed similarity at a level of $22 \%$, while V33 and V39 indicated $7.1 \%$ similarity.V13 and V15 exhibited $1.2 \%$ level of similarity. Few genotypes showed similarity in the range of 15 to $35.8 \%$, while most genotypes exhibited similarity ranging between 1.2 and $8 \%$ as indicated in Figure 1.

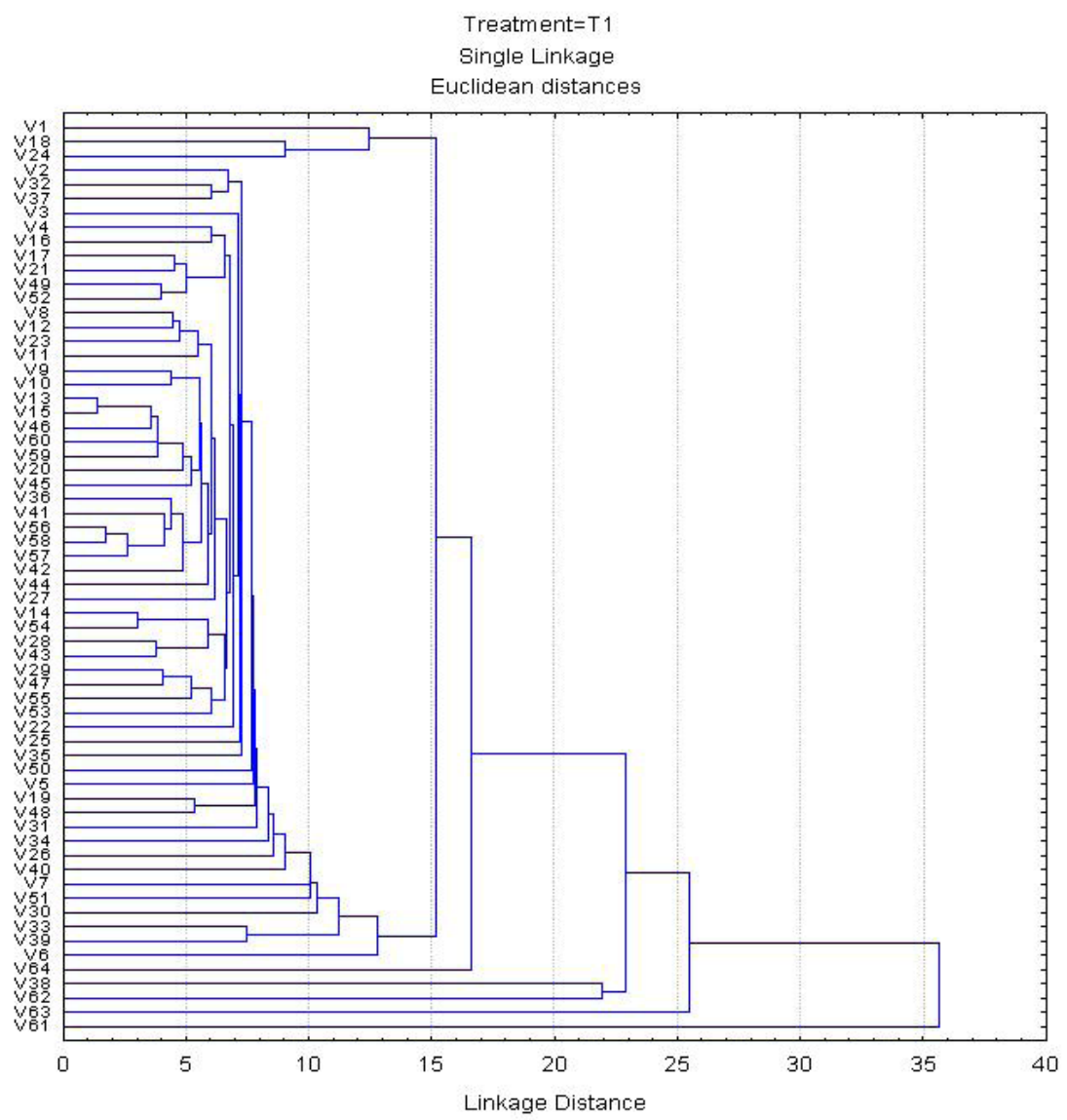

Figure 1. Dendrogram resulting from single linkage cluster analysis of 64 genotypes of Zea mays L. under T1 (40\% soil moisture condition).

Dendrograms resulting from single linkage cluster analysis of 64 genotypes of Zea mays $\mathrm{L} .\left(\mathrm{T}_{1}, \mathrm{~T}_{2}, \mathrm{~T}_{3}\right.$ and $\left.\mathrm{T}_{4}\right)$

The $24.4 \%$ level of similarity was only indicated by V20, which showed total dissimi- 
larity to the rest of all genotypes. V62 and V63 showed 13.5\% similarity, while V5 and V61 indicated $11.8 \%$ similarity.V53 and V54 exhibited 1.5\% similarity. Few genotypes showed a level of similarity in the range of 15.3 to $24.5 \%$, while most genotypes exhibited similarity ranging between 1.5 to $7 \%$ as indicated in Figure 2 .

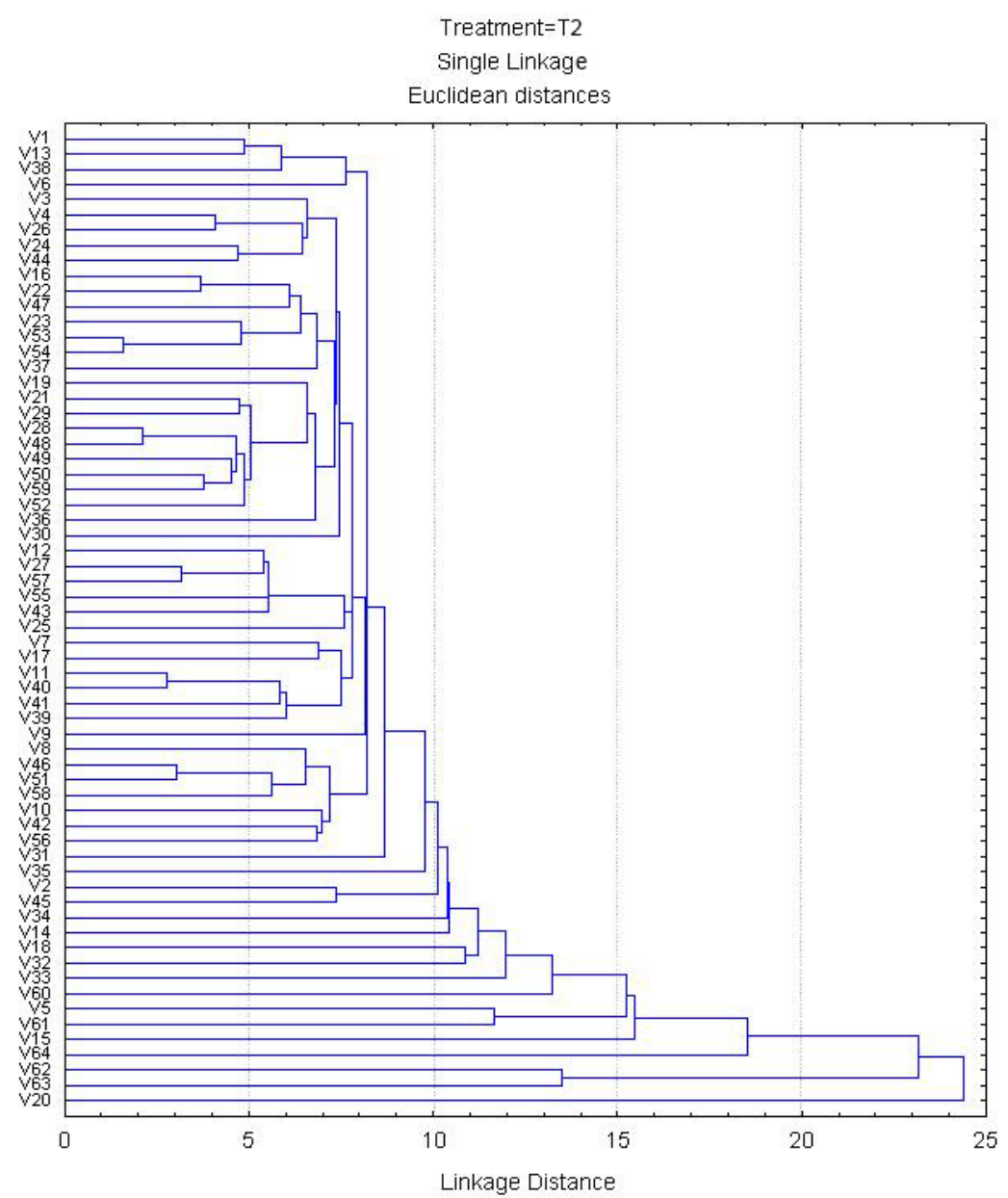

Figure 2. Dendrogram resulting from single linkage cluster analysis of 64 genotypes of Zea mays L. under T2 (60\% soil moisture condition).

The $20.8 \%$ level of similarity was only indicated by V64, which showed total dissimilarity to the rest of the genotypes. V34 and V58 showed similarity at the level of 7.2\%, while V5 and V62 indicated 2.4\% similarity. V53 and V55 exhibited 1.2\% similarity. Few genotypes showed a level of similarity in the range of 11 to $20.8 \%$, while most genotypes exhibited similarity ranging between 1.2 and $11 \%$ as indicated in Figure 3. 


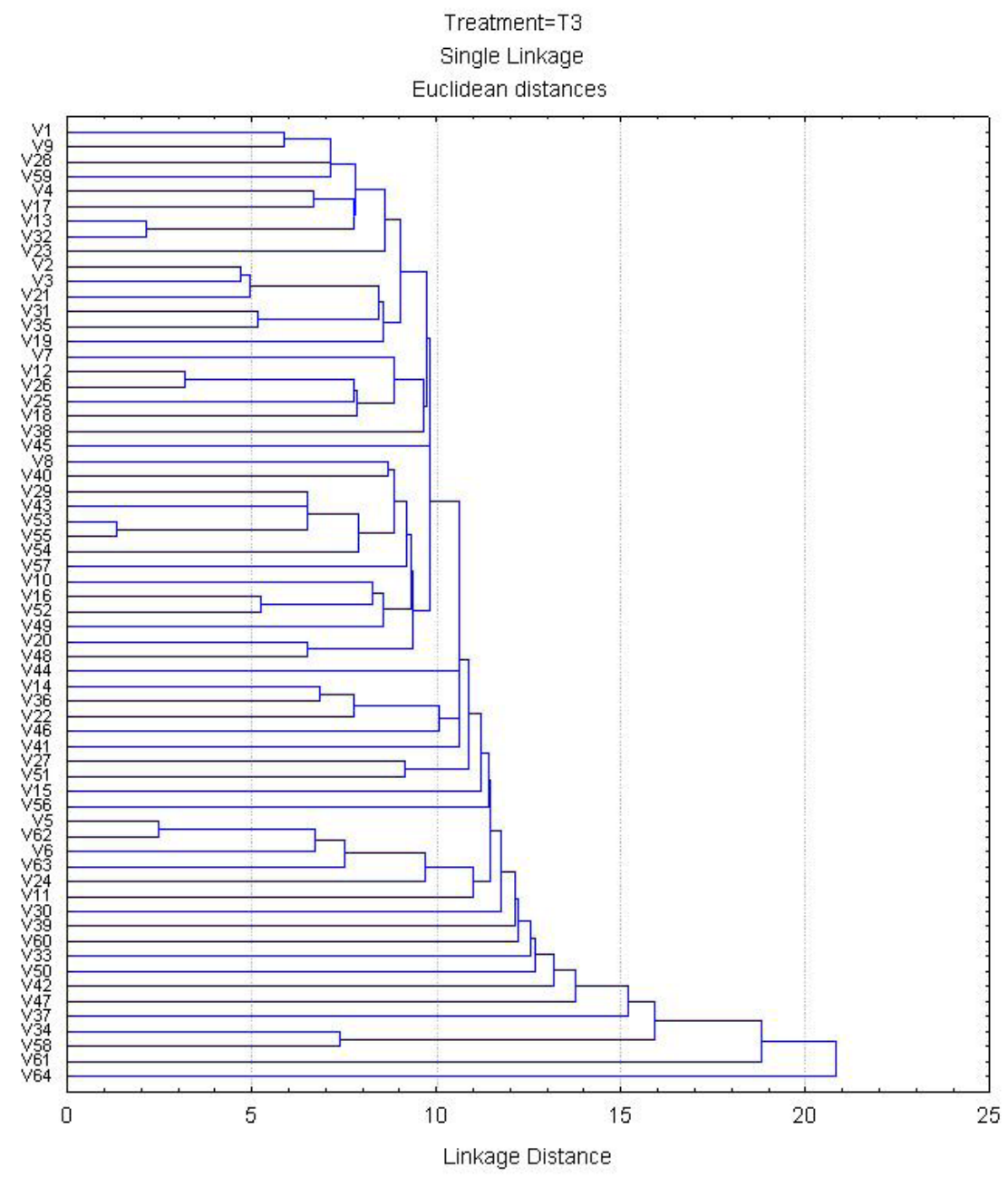

Figure 3. Dendrogram resulting from single linkage cluster analysis of 64 genotypes of Zea mays L. under T3 (80\% soil moisture condition).

The $31 \%$ level of similarity was only indicated by V60, which showed total dissimilarity to the rest of the genotypes. V56 and V58 showed similarity at the level of $10.5 \%$, while V34 and V39 indicated 7.9\% similarity. V15 and V42 exhibited $2.1 \%$ similarity. Few genotypes showed a level of similarity in the range of 10.5 to $31 \%$, while most genotypes exhibited similarity ranging between 2.1 and $7.9 \%$ as indicated in Figure 4.

Cluster analysis grouped together genotypes with greater genetic similarity and variability. The desirable genotypes may be chosen from particular groups for further breeding program. Clusters with superior agronomic types have been identified which could be exploited for genetic potential and then could be used to transfer the desirable genes to improve yield potential of the crop. 


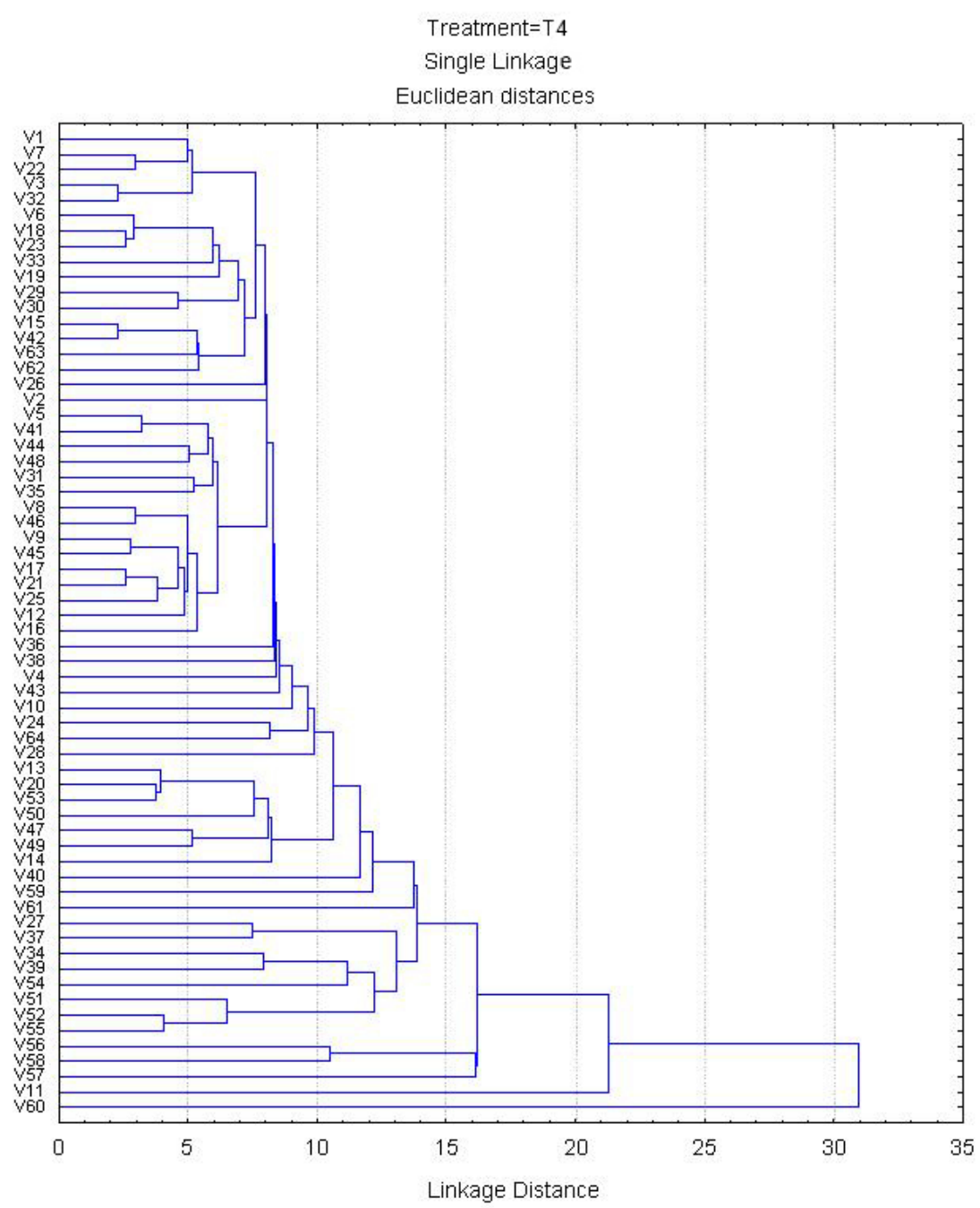

Figure 4. Dendrogram resulting from single linkage cluster analysis of 64 genotypes of Zea mays L. under T4 (100\% soil moisture condition).

\section{CONCLUSIONS}

The highest estimates of heritability were found for all characters under all moisture levels tested, which indicated that selection can be made on the basis of all these seedling characters. Genotypically, maximal pairs of characters showed a positive and significant correlation with each other, while phenotypically, these were highly significant in the case of all soil moisture levels under study. Some negative and non-significant correlations also existed from a genotypic and phenotypic point of view regarding $\mathrm{T}_{3} 80 \%$ and $\mathrm{T}_{4} 100 \%$, which were small in number. The first two, four, three and again three components, with eigenvalues $>1$ 
contributed $75.05,80.11,68.67$ and $75.87 \%$ of the variability between the genotypes under the different moisture levels. i.e., $\mathrm{T}_{1} 40 \%, \mathrm{~T}_{2} 60 \%, \mathrm{~T}_{3} 80 \%$ and $\mathrm{T}_{4} 100 \%$, respectively. Other PCs (3-10, 5-10, 4-10 and again 4-10) had eigenvalues less than 1 . It was also concluded that the characters LV, RV, LRL, RFW, SFW, RDW, SDW, SR and PH were positively correlated at the genotypic level and that they could be used for selection of better yielding lines under drought stress conditions.

\section{ACKNOWLEDGMENTS}

Research supported by the Pakistan Agriculture Research Council, Government of Pakistan. We are also grateful to Drs. Rao Iftikhar Ahmad, Rao Asif Ali, F.M. Azhar and Saleem Khan, Department of Plant Breeding and Genetics, University of Agriculture, Faisalabad, for extending technical knowledge and support regarding particular studies. We are also thankful to Dr. M. Shahid Massood, Director, Institute of Agricultural Biotechnology and Genetic Resources, NARC, Islamabad and Dr. Khadim, Maize and Millet Research Institute, Sahiwal for kindly supplying seeds of maize accessions. Thanks are also due to Dr. Sohail, Department of Statistics, for providing the statistical computer programs.

\section{REFERENCES}

Anonymous (2009-2011). Economic Survey of Pakistan. Govt. of Pakistan, Finance and Economic Affairs Division, Islamabad.

Araus JL, Slafer GA, Reynolds MP and Royo C (2002). Plant breeding and drought in C3 cereals: what should we breed for? Ann. Bot. 89 Spec No: 925-940.

Boyer JS (1970). Leaf enlargement and metabolic rates in corn, soybean, and sunflower at various leaf water potentials. Plant Physiol. 46: 233-235.

Camacho RG and Caraballo DF (1994). Evaluation of Morphological Characteristics in Venezuelan Maize (Zea mays L.) Genotypes Under Drought Stress. Dept. of Land and Environment U.R.G., Guarico.

Chaudhary RR and Joshi BK (2005). Correlation and path coefficient analysis in sugarcane. Nepal Agric. Res. J. 6: 24-27.

Dasgupta T, Islam MO and Gayen P (1992). Genetic variability and analysis of yield components in chickpea (Cicer arietinum L.). Ann. Agric. Res. 13: 157-160.

Denby K and Gehring C (2005). Engineering drought and salinity tolerance in plants: lessons from genome-wide expression profiling in Arabidopsis. Trends Biotechnol. 23: 547-552.

Echarte L and Tollenaar M (2006). Kernel set in maize hybrids and their inbred lines exposed to stress. Crop Sci. 46: 870-878.

Ghooshchi F, Seilsepour M and Jafri P (2008). Effects of water stress on yield and some agronomic traits of maize SC 301. Am. Eurasian J. Agric. Environ. Sci. 4: 302-305.

Kwon SH and Torrie JH (1964). Heritability and interrelationship of two soybean (Glycine max L.) populations. Crop Sci. 4: 196-198.

Malik HN, Malik SI, Hussain M, Chughtai SUR, et al. (2005). Genetic correlation among various quantitative characters in maize (Zea mays L.). Hybrids J. Agric. Social Sci. 3: 262-265.

Ojo DK, Omikunle OA, Oduwaye OA, Ajala MO, et al. (2006). Heritability, character correlation and path coefficient analysis among six inbred-lines of maize (Zea mays L.). World J. Agric. Sci. 2: 352-358.

Panhwar RN, Keerio HK, Khan MA, Rajpute MA, et al. (2003). Relationship between yield and yield contributing traits in sugarcane (Saccharum officinarum L.). Pak. J. Appl. Sci. 3: 97-99.

Sneath PHA and Sokal RR (1973). Numerical Taxonomy: The Principles and Numerical Classification. W. Freeman and Co., San Francisco.

Steel RGD, Torrie JH and Dickey (1997). Principles and Procedures of Statistics, a Biometrical Approach. McGraw Hill Book Co., New York.

Trester M and Bacic A (2005). Abiotic stress tolerance in grasses, from model plants to crop plants. Plant Physiol. 137: 791-793. 